\section{A Model for Scheduling Flowering of a Limonium sinuatum $\times$ Limonium perezii Hybrid}

\author{
Jianyu Chen ${ }^{1}$ and Keith A. Funnell ${ }^{2,3}$ \\ Institute of Natural Resources, Massey University, Private Bag 11-222, \\ Palmerston North, New Zealand
}

\section{Ed R. Morgan \\ The New Zealand Institute for Plant \& Food Research Limited, Private Bag 11-600, Palmerston North, New Zealand}

Additional index words. statice, daily light integral, leaf number accumulation rate, ground cover index, predictive model

\begin{abstract}
Observations of leaf number accumulation rate (LNAR) and light integrals (DLI) were used to develop a predictive model for time to flower for a novel hybrid of Limonium sinuatum (L.) Mill. $\times$ Limonium perezii (Stapf) Hubb. Plants were established in a temperature-controlled greenhouse at seven planting times from fall to late spring. Long days were maintained using daylength extension lighting. Two light regimes, full sun or $50 \%$ shade, were also used. DLI was highly correlated with the time to appearance of the first visible flower bud, explaining in excess of $80 \%$ of the variation. When combined with plant growth variables describing either LNAR or rates of increase in groundcover index, a second model was able to predict the date of first visible flowers and accounted for more variation than DLI alone. Daily average temperature (DAT) did not significantly contribute to variation in time to first visible flower because temperatures were uniform between successive plantings at 18 to $21.7^{\circ} \mathrm{C}$. However, DAT was significant for the period from visible flower through to flower harvest maturity. Growers of these hybrids for cut flowers can therefore use historical records of DLI to determine planting dates to schedule flowering. Once planting has occurred, by measuring actual DLI, DAT, and leaf number per plant, growers can use the second model to more accurately predict the dates for visible flowers and flower harvest.
\end{abstract}

A series of interspecific and back-cross hybrids have been developed for Limonium sinuatum (L.) Mill. $\times$ Limonium perezii (Stapf) Hubb. (Morgan et al., 2009) for commercial release. Production of many flower crops is scheduled and monitored to ensure their harvest times target specific market windows such as holidays. In contrast, cut flower crops like Limonium are produced and marketed over an extended season. Multiple planting dates through the year provide an opportunity to spread the harvest period to meet this market demand, but typically means crops are planted into different environments of light and temperature. Although it is frequently cost-effective to maintain temperature in a suitable range for production, this is less frequently so for light

\footnotetext{
Received for publication 21 May 2010. Accepted for publication 21 July 2010 .

We thank Maike Bendall for statistical advice and staff at the Plant Growth Unit, Massey University, for maintaining the controlled environment facilities used in this study.

${ }^{1}$ Former graduate student. Current address: Institute of Molecular and Biosciences, Massey University, Private Bag 11222, Palmerston North, New Zealand. ${ }^{2}$ Current address: The New Zealand Institute for Plant \& Food Research Limited, Private Bag 11-600, Palmerston North, New Zealand.

${ }^{3}$ To whom reprint requests should be addressed; e-mail k.funnell@massey.ac.nz.
}

(Faust, 2003). Development of reliable models for scheduling flowering requires an understanding of the environmental requirements for flower induction and development through to anthesis (Funnell, 2008; Oh et al., 2009).

Limonium sinuatum has been reported as a facultative, long-day plant with a critical photoperiod of $13 \mathrm{~h}$ (Semeniuk and Krizek, 1972; Shillo and Zamski, 1985). Long days are also likely to promote flowering of $L$. perezii (Armitage, 2003), albeit this response has not been quantified.

Daily light integral (DLI), being the product of photosynthetic photon flux $(P P F)$ and photoperiod, has been used successfully as a light variable in models developed for crop scheduling (Oh et al., 2009; Warner and Erwin, 2003). Although L. sinuatum has been reported as being indifferent to DLI (Mattson and Erwin, 2005), researchers examined DLI values between 15.3 and $27.6 \mathrm{~mol} \cdot \mathrm{m}^{-2} \cdot \mathrm{d}^{-1}$ in which DLI may not have been limiting. Other workers have reported a response to DLI during periods of naturally low light intensity (Shillo and Zamski, 1985). In mainland United States, crops can be exposed to DLI values ranging from 4 to $60 \mathrm{~mol} \cdot \mathrm{m}^{-2} \cdot \mathrm{d}^{-1}$ (Korczynski et al., 2002). A similar range is encountered within New Zealand. At the lower extreme of this range, these DLI values can limit commercial production of numerous greenhouse crops (Faust, 2003).
A facultative vernalization response is evident for cultivars of L. sinuatum (Semeniuk and Krizek, 1973) with subsequent growth rate increased at higher temperatures of 22 to $27^{\circ} \mathrm{C}$ day and 12 to $16^{\circ} \mathrm{C}$ night. In contrast, $L$. perezii is reported as being "free-flowering" (Harada, 1992); we interpret this to mean that vernalization is not a requirement for flowering in this species. As used in the current experiment, hybrids between these two species have been successfully grown to flower in greenhouses maintained at temperatures between 15 and $20^{\circ} \mathrm{C}$ without vernalization (unpublished data).

Plant growth variables have been successfully incorporated into models for predicting timing of flowering, acknowledging the potential for differences in leaf number and dry matter accumulation in response to DLI (Heins et al., 2000; Liu and Heins, 2002; Warner and Erwin, 2003). Growth variables such as leaf number below the inflorescence are particularly useful in interpreting the environmental response of plants with a determinate shoot growth habit (like Limonium), because it can be used as an indicator of the transition from vegetative to floral growth. Furthermore, the flowering of plants has been proposed to occur when photosynthetic leaf area reaches a critical threshold with leaf area and flowering time being significantly correlated (Armitage, 1984; Ramina et al., 1979). Thus, in the current study, attempts were made to examine the potential for combinations of plant growth variables and environmental factors to predict flowering.

The objective of this research was to develop and validate a model to predict time to flower of a novel Limonium hybrid based on environmental factors (primarily DLI) and/or plant growth variables (e.g., leaf number and groundcover index).

\section{Materials and Methods}

Plant materials and production. Plants of the Limonium hybrid designated 'LPLS4', propagated by tissue culture, were deflasked and grown in a greenhouse in 50-cell trays ( $85 \mathrm{~mL}$ cell volume) for 5 to 8 weeks to reach transplant size (i.e., an average $10 \pm 2$ leaves and $8 \pm 2 \mathrm{~cm}$ rosette diameter). Cell trays contained a soilless medium (bark:pumice, $50: 50)$ plus $4.3 \mathrm{~kg} \cdot \mathrm{m}^{-3}$ Osmocote $(16 \mathrm{~N}-$ 3.5P-10K; Grace-Sierra International, Heerlen, The Netherlands), $5 \mathrm{~kg} \cdot \mathrm{m}^{-3}$ dolomite $(21 \mathrm{Ca}-$ 10Mg; Prebbles Seeds, Christchurch, New Zealand), $1 \mathrm{~kg} \cdot \mathrm{m}^{-3}$ superphosphate $(9.1 \mathrm{P}$ $11 \mathrm{~S}-20 \mathrm{Ca}), 0.2 \mathrm{~kg} \cdot \mathrm{m}^{-3}$ calcium ammonium nitrate $(27 \mathrm{~N}-6 \mathrm{Ca}-4 \mathrm{Mg}), 0.75 \mathrm{~kg} \cdot \mathrm{m}^{-3} \mathrm{PG}$ Mix $(14 \mathrm{~N}-16 \mathrm{P}-18 \mathrm{~K}-0.03 \mathrm{~B}-0.12 \mathrm{Cu}-0.35 \mathrm{Fe}-0.16$ $\mathrm{Mn}-0.2 \mathrm{Mo}-0.04 \mathrm{Zn}$; Hydro Agri Roterdam, Vlaardingen, The Netherlands), $0.5 \mathrm{~kg} \cdot \mathrm{m}^{-3}$ potassium sulphate $(42 \mathrm{~K}-18 \mathrm{~S})$, and $0.1 \mathrm{~kg} \cdot \mathrm{m}^{-3}$ Terrazole (Chemtura, Middlebury, CT). When the majority of transplants (i.e., 90\%) reached transplant size, they were repotted into $1.5-\mathrm{L}$ plastic pots containing a 50:30:20 bark:peat: pumice mixture plus $2.0 \mathrm{~kg} \cdot \mathrm{m}^{-3}$ each of agricultural lime and dolomite and $3.0 \mathrm{~kg} \cdot \mathrm{m}^{-3}$ Osmocote $16 \mathrm{~N}-3.5 \mathrm{P}-10 \mathrm{~K}$. The plants were subsequently transferred to a greenhouse at 
the Plant Growth Unit, Massey University (Palmerston North, New Zealand; long. $40^{\circ} 20^{\prime} \mathrm{S}$ ).

During the course of the experiment, plants were grown on drained beds with capillary matting and irrigation was maintained to avoid water stress. Greenhouses were heated at $15^{\circ} \mathrm{C}$, ventilated at $20^{\circ} \mathrm{C}$, and received natural sunlight and photoperiod ( 9 to $15 \mathrm{~h}$ ). To avoid confounding effects of photoperiod on flowering, a longday environment (greater than $13 \mathrm{~h}$ ) was maintained within the greenhouse by supplying $4 \mathrm{~h}$ of night-break lighting from 2200 to $0200 \mathrm{HR}$ using incandescent lamps giving $2.4 \pm 0.4$ $\mu \mathrm{mol} \cdot \mathrm{m}^{-2} \cdot \mathrm{s}^{-1} P P F$ at plant canopy height.

Treatments and experimental design. Treatments comprised seven planting dates from May to Nov. 2003. At each planting date, two light levels were achieved by covering half the number of replicate plots with spectrally neutral, woven polypropylene shadecloth of nominal 50\% density (Sarlon; Donaghys Pty., Christchurch, New Zealand). The combination of planting dates and light levels (i.e., shade or no shade) resulted in treatments differing in average DLI from transplanting to flowering of 4 to $21 \mathrm{~mol} \cdot \mathrm{m}^{-2} \cdot \mathrm{d}^{-1}$.

Because a $50 \%$ reduction in light level during the months of lowest natural irradiance, i.e., June and July, was considered to be in excess of that encountered in commercial horticultural situations, only non-shaded treatments were used in these 2 months. Only the nonshaded treatment was used for the planting in November. Thus, there were 11 treatment combinations ( planting date $\times$ shade level) with three replicates (plots) for each treatment.

The experiment comprised 10 blocks, each measuring $1.2 \times 3.6 \mathrm{~m}$, with $50 \mathrm{~cm}$ between each block. Each of the six replicate plots per block contained 10 plants used for recording data with 18 guard plants surrounding each plot. All plants were placed next to each other in a plot or between plots in a block, resulting in plants being at centers of $17 \mathrm{~cm}$.

Data collection. Growth was monitored three times per week, and the dates of attainment of two phenological stages of development were noted, i.e., 1) first visible presence of a flower bud (i.e., $5 \mathrm{~mm}$ or greater in length); and 2) harvest maturity of the first stem $(80 \%$ calyces open). Duration from transplanting to the first visible flower bud (DTV; i.e., Phase 1) of each plant was calculated. Duration to harvest (DTH; i.e., Phase 2) was calculated as the difference between the date of the first visible flower bud and the date of first harvest of a plant.

Air temperature was monitored using 10 shaded thermistors positioned at leaf canopy height and recorded at 10-min intervals ( $\mathrm{T}_{10 \mathrm{~min}}$ ) using a Squirrel 1200 Digital Meter/ Logger (Grant Instruments Ltd., Barrington, Cambridge, U.K). Daily average temperatures (DAT) were recorded throughout the experiment. A linear growing degree-days (GDD) model (Funnell, 2008) with a base temperature of $0{ }^{\circ} \mathrm{C}$ was used. Accumulated GDD from the date of transplanting $(t)$ until attainment of each of the phenological stages of development ( $a$ and $b$ ) were calculated using Eq. [1]:

$$
\mathrm{GDD}=\sum_{t}^{(a) \rightarrow(b)}\left[\frac{\mathrm{T}_{10 \mathrm{~min}}-\mathrm{T}_{\mathrm{BASE}}}{\mathrm{n}_{10 \min }}\right]
$$

where $\mathrm{n}_{10 \min }$ is the number of temperature recordings per day and where $\mathrm{T}_{\mathrm{BASE}}=0{ }^{\circ} \mathrm{C}$.

GDD during Phases 1 and 2 as well as calendar days for the same were analyzed using a generalized linear routine (PROC GLM) within the Statistical Analysis System (SAS Institute, Cary, NC).

$P P F$ was measured every 5 min using a quantum sensor (LI 190S; LI-COR Inc., Lincoln, NE) at canopy height in representative shaded and non-shaded plots. The sensors were linked to a light meter (LI-1000; LI-COR Inc.). Recordings of $P P F$ were integrated to calculate DLI with cumulative daily light integrals (CDLI) for both Phases 1 and 2 calculated by summing DLI over the relevant periods. Also, average daily light integrals (ADLI) occurring over Phases 1 and 2 were calculated as the numerical average of DLI encountered.

Once transferred to the greenhouse, the accumulated leaf number (i.e., leaves $5 \mathrm{~mm}$ or greater in length) on the main shoot of each plant was counted once per week until there was no change in leaf number for 7 weeks. The maximum leaf number (MLN), below the first visible flower bud, was calculated as the numerical average for each plot of 10 plants. During Phase 1, leaf number accumulation rate (LNAR) was derived from the slope of the straight-line equation describing changes in average leaf number per plot over time (GENSTAT 7, VSN International Ltd., Hemel Hempstead, U.K.).

Ground cover index (GCI), i.e., the proportion of ground in a plot covered by leaf area, was recorded throughout Phase 1. Each plot was photographed weekly using a digital camera (Fuji 2100; Fujifilm Corporation, Tokyo, Japan) from directly above incorporating a 1$\mathrm{cm}^{2}$ object for scaling. Images were processed and analyzed using Corel Photo-Paint (Corel Corporation, Ottawa, Canada) and SigmaScan Pro4 (SPSS, Chicago, IL) deriving a measure of both the visible leaf area and ground area in the processed image. In each plot, GCI was calculated as visible leaf area/ground area.

For each plot, changes of GCI with time were described using a Gompertz function using Eq. [2] resulting from the biological significance of key parameters and goodness of fit. The parameter $\mathrm{B}$, describing the groundcover index rate (GCIR), was chosen as a potential predictor of DTV for further data analysis.

$$
\mathrm{GCI}=\mathrm{A}+\mathrm{C} e^{\left\{-e^{[\mathrm{B}(\mathrm{M}-\mathrm{t})]}\right\}}
$$

where:

$\mathrm{A}=$ lower asymptote of GCI $\left(\mathrm{cm}^{2} \cdot \mathrm{cm}^{-2}\right)$;

$\mathrm{C}=$ upper asymptote of GCI $\left(\mathrm{cm}^{2} \cdot \mathrm{cm}^{-2}\right)$;

$\mathrm{B}=\mathrm{GCI}$ increase rate (GCIR) over time $\left(\mathrm{cm}^{2} \cdot \mathrm{cm}^{-2} \cdot \mathrm{d}^{-1}\right)$

$\mathrm{t}=$ time (days); and

$\mathrm{M}=$ value of $\mathrm{t}$ at the point of inflection.

Rosette diameter (RD) of individual plants was measured from digital photographs taken weekly using SigmaScan Pro4 software. The
$\mathrm{RD}$ was calculated from the average of two measurements taken at right angles to each other.

Model development and validation. The environmental and plant growth variables showing a high level of correlation with DTV and/or DTH, i.e., ADLI, LNAR, GCIR, and MLN, were subjected to multiple regression analysis to determine if the initial predictive model using each variable on its own could be further improved. Variables such as RD, DAT, and CDLI were not included for further analysis because they were not highly correlated.

The regression models were validated using crossvalidation (Draper and Smith, 1981). In summary, a treatment was excluded from the data set and a model was constructed based on the data from the other 10 treatments. The model was then used to predict the data of the excluded treatment. This procedure was completed for each treatment in turn, and the predictive residual sum of squares (PRSS) was used to compare the models. The lower the value of PRSS, the higher the predictive power.

\section{Results}

Plants from all treatments flowered and produced a flower stem during the assessment period. DTV ranged from 52 to $165 \mathrm{~d}$, whereas DTH varied from 47 to $68 \mathrm{~d}$.

Environmental and plant growth variables. DLI ranged from 0.4 to $36 \mathrm{~mol} \cdot \mathrm{m}^{-2} \cdot \mathrm{d}^{-1}$ on individual days from 7 May 2003 to 24 Feb. 2004. Without shade in May, June, and July, DLI was relatively stable (less than 10 $\left.\mathrm{mol} \cdot \mathrm{m}^{-2} \cdot \mathrm{d}^{-1}\right)$, increasing significantly from August to February. For all treatments, in Phase 1 , ADLI ranged from 4 to $20 \mathrm{~mol} \cdot \mathrm{m}^{-2} \cdot \mathrm{d}^{-1}$ and from 4.2 to $20.6 \mathrm{~mol} \cdot \mathrm{m}^{-2} \cdot \mathrm{d}^{-1}$ in Phase 2 .

On any single day, DAT in the greenhouse rarely exceeded $24{ }^{\circ} \mathrm{C}$ or fell below $15{ }^{\circ} \mathrm{C}$. Within individual treatment environments, DAT remained relatively constant during the course of the experiment, varying from 18.6 to $20.9^{\circ} \mathrm{C}$ in Phase 1 and 18 to $21.7^{\circ} \mathrm{C}$ in Phase 2 .

MLN declined exponentially with increasing $\operatorname{ADLI}(P<0.0001$; Fig. 1A). The predicted MLN decreased by 10 leaves as ADLI increased from 4 to $9 \mathrm{~mol} \cdot \mathrm{m}^{-2} \cdot \mathrm{d}^{-1}$ and remained relatively constant between 28 and 29 leaves as ADLI increased from 9 to $20 \mathrm{~mol} \cdot \mathrm{m}^{-2} \cdot \mathrm{d}^{-1}$.

During Phase 1, LNAR increased exponentially as ADLI increased from 4 to $20 \mathrm{~mol} \cdot \mathrm{m}^{-2} \cdot \mathrm{d}^{-1}$ and explained $78 \%$ of the variation in LNAR $(P<0.0001$; Fig. 1B). Similarly during this phase, GCIR increased exponentially with increasing ADLI from 4 to $20 \mathrm{~mol} \cdot \mathrm{m}^{-2} \cdot \mathrm{d}^{-1}$ and explained $84.5 \%$ of the variation in GCIR $(P<$ 0.0001; Fig. 1C).

Duration from transplanting to duration from transplanting to the first visible flower bud-environmental and plant variables as predictors. DTV decreased exponentially with increasing ADLI and, by itself, explained in excess of $88 \%$ of the variation in DTV $(P<$ 0.0001; Fig. 1D). CDLI had no significant correlation with DTV $(P=0.79)$.

GDD accumulated during DTV varied between 1021 and 3212 GDD. Although a significant linear relationship was found between GDD and DTV $(P<0.0001)$, there was no 

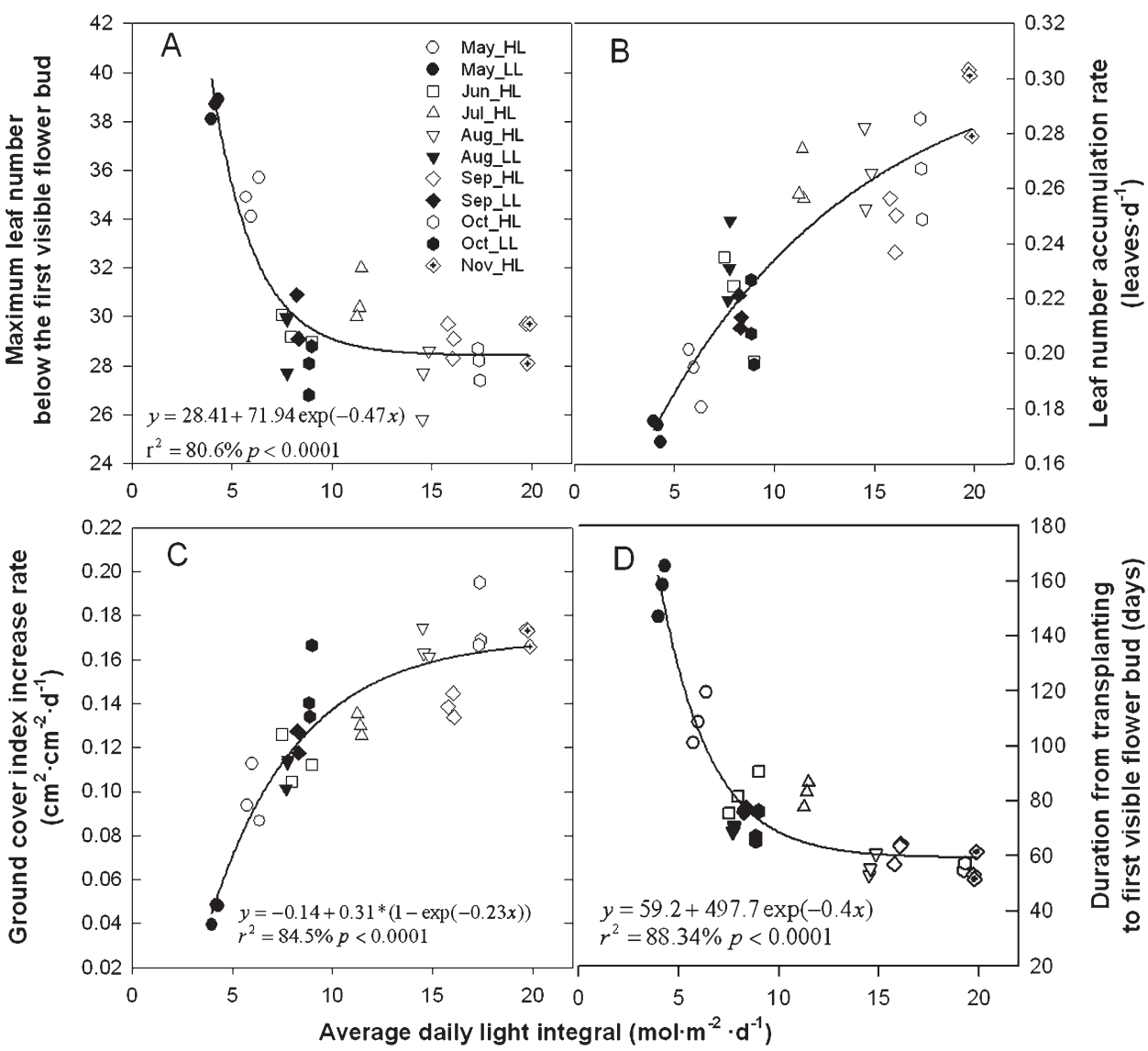

Fig. 1. Relationships between average daily light integral during Phase 1 and maximum leaf number (A), leaf number accumulation rate (B), groundcover index increase rate $(\mathbf{C})$, and duration from transplanting until first visible flower bud (D). Each data point is the average for 10 plants in a replicate plot.

clear correlation between DTV and DAT. Given the uniformity of air temperatures during the experiment, the correlation between GDD and DTV was considered to be a mathematical artifact rather than of biological significance.

DTV decreased exponentially as LNAR increased $(P<0.0001 ;$ Fig. 2A). The predicted DTV decreased by $\approx 90 \mathrm{~d}$ as LNAR increased from 0.16 to 0.22 leaves per day, whereas the further increase of LNAR from 0.22 to 0.3 leaves per day only reduced the predictive DTV by 30 d, i.e., the plateau appeared within this range.

GCIR and DTV were correlated $(P<$ $0.0001)$. The predictive DTV decreased exponentially from 165 to $50 \mathrm{~d}$ as GCIR increased from 0.04 to $0.2 \mathrm{~cm}^{2} \cdot \mathrm{cm}^{-2} \cdot \mathrm{d}^{-1}$ (Fig. 2B). In contrast to LNAR, there was no plateau on the curve of DTV against GCIR within the data range examined.

DTV increased exponentially with increasing values of MLN $(P<0.0001$; Fig. $2 \mathrm{C})$.

Multiple regression model predicting $d u$ ration from transplanting to the first visible flower bud. The probability for adding both ADLI and GCIR into the model was not significant for the coefficient associated with ADLI $(P=0.21$; Table 1$)$. However, the model with the highest $r^{2}$ (i.e., 92.5\%) incorporated both ADLI and LNAR as predictors (Fig. 3) with probabilities for the coefficients involving both ADLI and LNAR being significant (Table 1).
Crossvalidation of the predictive models for DTV using ADLI only, or both ADLI and LNAR, resulted in PRSS values of 4578 and 3970 , respectively. The model containing both ADLI and LNAR had the lower PRSS value, validating the model and confirming that it had the greatest predictive power.

Duration from duration from transplanting to the first visible flower bud to harvest. Across all treatments, DTH varied from 47 to $68 \mathrm{~d}$. The shortest DTH was recorded from the planting in November under full sun (i.e., the treatment with the highest ADLI of 20 $\left.\mathrm{mol} \cdot \mathrm{m}^{-2} \cdot \mathrm{d}^{-1}\right)$. The longest DTH was recorded from the planting in May with 50\% shade (i.e., the treatment with the lowest ADLI of $\left.4 \mathrm{~mol} \cdot \mathrm{m}^{-2} \cdot \mathrm{d}^{-1}\right)$. Because of the substantial variation in DTH, especially for those treatments resulting in higher ADLI values (14 d), there was no significant correlation between DTH and ADLI. There was also no significant correlation between DTH and CDLI $(P=0.88)$.

There was a general trend toward shorter DTH with increasing temperature, although with the narrow range of DAT values encountered in this study, the correlation was understandably poor $(P=0.84)$. GDD accumulated during DTH varied from 1022 to $1324{ }^{\circ} \mathrm{C} \cdot \mathrm{d}^{-1}$.

\section{Discussion}

Average daily light integral as a predictor of duration or rate of progress to duration from transplanting to the first visible flower bud. ADLI is one of the main factors that influenced the DTV of 'LPLS4' and, by itself, explained in excess of $88 \%$ of the variation within the current experiment. Flowering occurred in all plants even with ADLI during Phase 1 as low as $4 \mathrm{~mol} \cdot \mathrm{m}^{-2} \cdot \mathrm{d}^{-1}$, suggesting that if there is a minimum ADLI requirement for flower initiation of 'LPLS4', it is less than $4 \mathrm{~mol} \cdot \mathrm{m}^{-2} \cdot \mathrm{d}^{-1}$. As ADLI increased from 4 to $10 \mathrm{~mol} \cdot \mathrm{m}^{-2} \cdot \mathrm{d}^{-1}$, DTV was reduced by $\approx 90 \mathrm{~d}$, which was significantly greater than the 8-d reduction with pansy (Niu et al., 2000) and 3 $\mathrm{d}$ with Achillea $\times$ millefolium L. (Fausey et al., 2005) for the comparable increase in ADLI. However, for 'LPLS4', the response of DTV to ADLI was saturated above $15 \mathrm{~mol} \cdot \mathrm{m}^{-2} \cdot \mathrm{d}^{-1}$ (Fig. 1D). Mattson and Erwin (2005) also reported no difference in days to first flower of $L$. sinuatum when grown above $15.3 \mathrm{~mol} \cdot \mathrm{m}^{-2} \cdot \mathrm{d}^{-1}$. Hence, within the context of DLI values experienced commercially (i.e., between 5 and $60 \mathrm{~mol} \cdot \mathrm{m}^{-2} \cdot \mathrm{d}^{-1}$; Korczynski et al., 2002), 'LPLS4' is not classified as an irradiance indifferent plant.

The increase in ADLI from 4 to 20 $\mathrm{mol} \cdot \mathrm{m}^{-2} \cdot \mathrm{d}^{-1}$ not only accelerated the date of flowering of 'LPLS4', but also the rate of other growth variables, quantified here as LNAR and GCIR. As well as a reduced DTV, plants under higher ADLI had faster rates of both leaf appearance (Fig. 1B) and expansion of leaf area (Fig. 1C). This finding supports a hypothesis that ADLI levels supporting the most rapid rate of vegetative growth of 'LPLS4' result in 


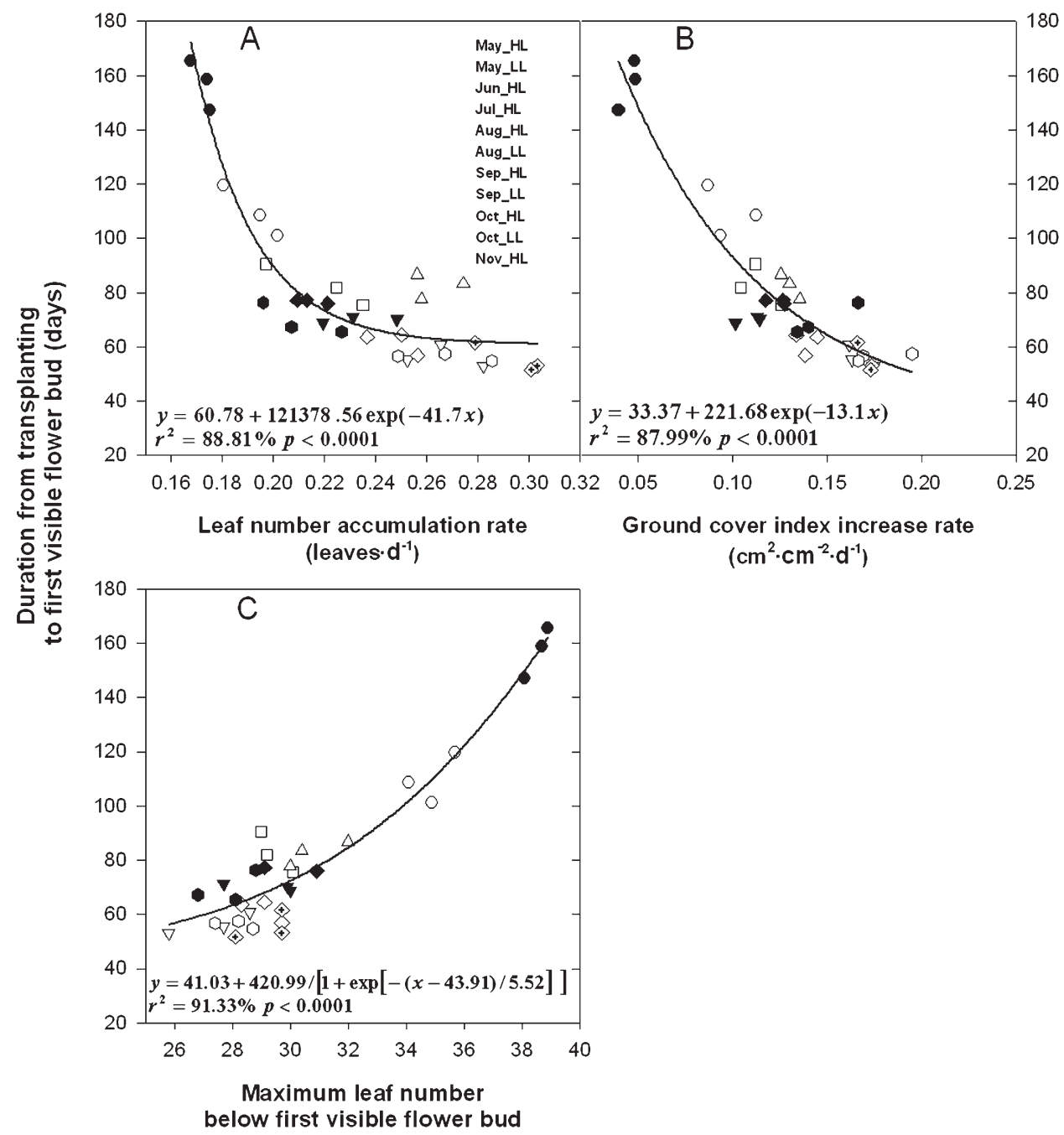

Fig. 2. Duration from transplanting until the first visible flower bud of 'LPLS4' as a function of leaf number accumulation rate (A), groundcover index increase rate $(\mathbf{B})$, and maximum leaf number below the first visible flower $(\mathbf{C})$. Each data point is the average of 10 plants in a replicate plot.

Table 1. Regression models predicting duration from transplanting to the first visible flower bud (DTV) as a function of average daily light integral (ADLI), leaf number accumulation rate (LNAR), and/or groundcover index increase rate (GCIR).

\begin{tabular}{llll}
\hline Predictors & \multicolumn{1}{c}{ Model } & $r^{2}$ & Predictor \\
\hline ADLI & DTV $=59.2+497.7 * \operatorname{Exp}(-0.4 *$ ADLI & $88.34 \%$ & $P<0.0001$ \\
LNAR & DTV $=60.78+121378.56 * \operatorname{Exp}(-41.7 *$ LNAR $)$ & $88.81 \%$ & $P<0.0001$ \\
GCIR & DTV $=33.37+221.68 * \operatorname{Exp}(-13.1 *$ GCIR $)$ & $87.99 \%$ & $P<0.0001$ \\
ADLI, LNAR & DTV $=59.01+6578^{*} \operatorname{Exp}(-0.1891 *$ ADLI $-19.82 *$ LNAR $)$ & $92.5 \%$ & $P<0.01$ \\
ADLI, GCIR & DTV $=49.55+262.4 * \operatorname{Exp}\left(-0.0966^{*}\right.$ ADLI-11.13*GCIR $)$ & $89.3 \%$ & $P=0.21$ \\
\hline
\end{tabular}

optimal or fast flower initiation; more specifically, that some of the shortest durations to flower initiation in 'LPLS4' will occur at ADLI of $15 \mathrm{~mol} \cdot \mathrm{m}^{-2} \cdot \mathrm{d}^{-1}$ or greater, a GCIR of $0.16 \mathrm{~cm}^{2} \cdot \mathrm{cm}^{-2} \cdot \mathrm{d}^{-1}$ or greater, and/or a LNAR 0.26 leaves per day or greater.

A saturation response to the exponential increase in LNAR with increasing ADLI has commonly been reported with other crop species (Volk and Bugbee, 1991), albeit the actual point of saturation was not encountered in the current experiment (Fig. 1B). With wheat and barley, saturation of the response of LNAR was obtained at $\approx 30 \mathrm{~mol} \cdot \mathrm{m}^{-2} \cdot \mathrm{d}^{-1}$ (Volk and Bugbee, 1991). Because $20 \mathrm{~mol} \cdot \mathrm{m}^{-2} \cdot \mathrm{d}^{-1}$ was the maximum ADLI encountered in the current experiment, further research is required to determine the point of saturation with 'LPLS4'.
The influence of ADLI varied in different development stages of 'LPLS4', which, in the current study, has been classified into Phase 1 (from transplanting to first visible flower bud) and Phase 2 (from first visible flower bud to harvest). ADLI significantly affected the rate of vegetative growth and DTV in Phase 1 (Fig. 1B-D), whereas it had no evident correlation with DTH in Phase 2. ADLI is, therefore, more influential in the process of vegetative growth through flower initiation and appearance than in the subsequent phase of flower bud development to harvest. This finding is similar to that reported for geranium (Armitage et al., 1981) and Rosa hybrida (Pasian and Lieth, 1994), in which time required from visible bud to anthesis was not correlated with ADLI.
Effect of temperature. During the current experiment, DAT in the greenhouse was restricted to the range of 18 to $21.7^{\circ} \mathrm{C}$. Whereas no correlation was detected between average DAT and DTV, the potential for faster growth rates with $L$. sinuatum at higher temperatures than used in the current experiment (Semeniuk and Krizek, 1973) highlights the need for future studies to incorporate a temperature response into future applications of the models developed here. Given the established influence of temperature on rate of development to flowering of other crops (Heins et al., 2000; Pasian and Lieth, 1994), the lack of correlation in the current study further confirms that any confounding effect of DAT on DTV was removed by restricting DAT to a narrow range. 


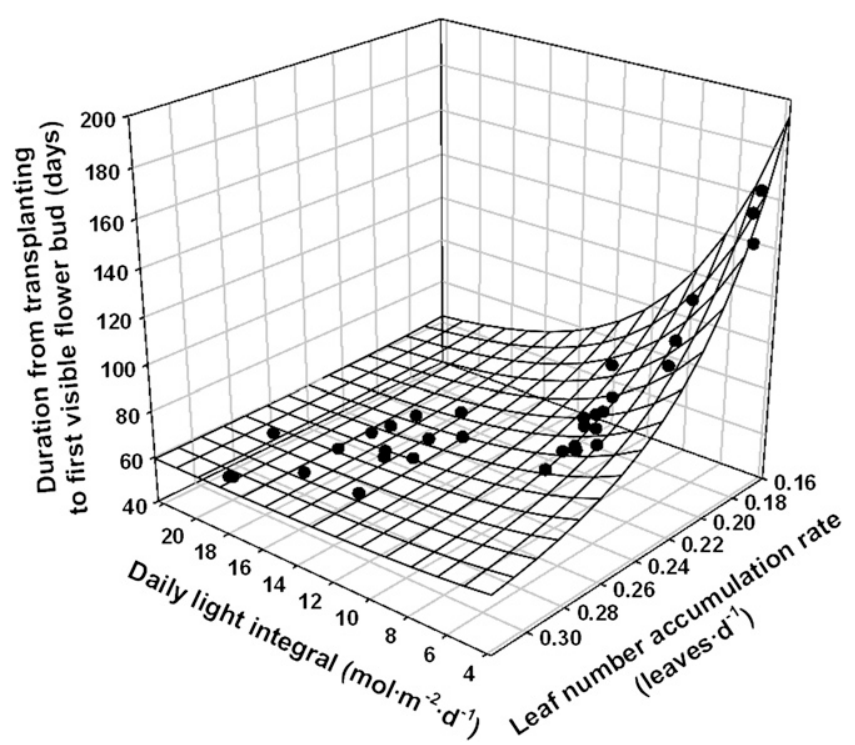

Fig. 3. Relationship between average daily light integral, leaf number accumulation rate, and duration from transplanting to the first visible flower bud. The response surface was fitted by regression analysis, in which DTV $=59.01+6578 * \mathrm{EXP}(-0.1891 * \mathrm{ADLI}-19.82 * \mathrm{LNAR}), r^{2}=92.5 \%$. DTV $=$ duration from transplanting to the first visible flower bud; ADLI $=$ average daily light integral; LNAR $=$ leaf number accumulation rate.

Is a specific leaf number required for flower initiation of 'LPLS4'? A specific or minimum leaf number has been suggested as a requirement for flower initiation in a number of plant species (Mattson and Erwin, 2005). In this study, the maximum leaf number below the inflorescence varied from 27 to 39 leaves but was highly dependent on ADLI during Phase 1 (Fig. 1A). Plants grown under an ADLI of $9 \mathrm{~mol} \cdot \mathrm{m}^{-2} \cdot \mathrm{d}^{-1}$ or greater achieved a more consistent leaf number of 28 or 29 leaves. This infers that under favorable growing conditions (i.e., ADLI $9 \mathrm{~mol} \cdot \mathrm{m}^{-2} \cdot \mathrm{d}^{-1}$ or greater, DAT $20^{\circ} \mathrm{C}$, and long photoperiods), 'LPLS4' accumulates a specific number of leaves before flower initiation. This finding is in agreement with the conclusions of Mattson and Erwin (2005), in which there was no difference in leaf number for $L$. sinuatum grown under long days with ADLI ranging from 15.3 to 27.6 $\mathrm{mol} \cdot \mathrm{m}^{-2} \cdot \mathrm{d}^{-1}$. In the current study, however, at ADLI less than $9 \mathrm{~mol} \cdot \mathrm{m}^{-2} \cdot \mathrm{d}^{-1}$, the relationship with leaf number does not hold, and a significant increase of maximum leaf number was found as the ADLI decreased from 9 to $4 \mathrm{~mol} \cdot \mathrm{m}^{-2} \cdot \mathrm{d}^{-1}$. This increase in MLN corresponded with the significant delay of DTV under ADLI less than $9 \mathrm{~mol} \cdot \mathrm{m}^{-2} \cdot \mathrm{d}^{-1}$. Thus, it is possible that the presence of some promoters for flower initiation in 'LPLS4' appeared to be inhibited or postponed under ADLI less than $9 \mathrm{~mol} \cdot \mathrm{m}^{-2} \cdot \mathrm{d}^{-1}$, which resulted in the continuation of vegetative growth, i.e., leaf number accumulation, and greater MLN. Future research might also investigate this as a hypothesis.

The consistency of the leaf number before flower initiation of 'LPLS4' can be used as a predictor of DTV under growing conditions in which ADLI during Phase 1 is greater than $9 \mathrm{~mol} \cdot \mathrm{m}^{-2} \cdot \mathrm{d}^{-1}$. However, this prediction can only be accurate when ADLI values range from 9 to $15 \mathrm{~mol} \cdot \mathrm{m}^{-2} \cdot \mathrm{d}^{-1}$, because above $15 \mathrm{~mol} \cdot \mathrm{m}^{-2} \cdot \mathrm{d}^{-1}$, no further reduction in DTV occurs regardless of increases in LNAR. This suggests that the combination of plant growth variables (e.g., LNAR) with ADLI might be a more precise way to explain variations in DTV.

Correlation between variables and models predicting duration from transplanting to the first visible flower bud. The rate of vegetative was highly correlated with DTV for 'LPLS4'. The faster the rate of leaf appearance, and expansion of leaf area, the shorter the DTV (Fig. 2A-B). This suggests that the DTV of 'LPLS4' can be predicted by monitoring leaf number or leaf area in actual growing conditions. The significant association between DTV with LNAR or GCIR is contrary to findings for Primula vulgaris (Karlsson, 2002) and $P$. $\times$ domesticum (Loehrlein and Craig, 2004) in which faster leaf unfolding or leaf area enlargement did not result in earlier flower initiation. For $P$. vulgaris and $P . \times$ domesticum, these plant growth variables have limited application for predicting such critical stages of physiological development.

In the current study, data from the July planting date were an obvious outlier from the trend in the curve for DTV against LNAR (Fig. 2A). However, data from this treatment were not considered to be an outlier when plotted against GCIR (Fig. 2B), suggesting GCIR may offer a more accurate plant growth variable for modeling than LNAR. Because monitoring LNAR involves simply counting leaves, in contrast to monitoring GCIR, LNAR is more likely to be used by a greater number of growers.

One of the key objectives in this study was to develop a model to predict DTV for the novel hybrid 'LPLS4'. The sensitivity of 'LPLS4' to environmental factors, especially ADLI, should allow growers to use a range of planting dates and predict DTV based on the historical data of DLI (e.g., 30-year average monthly DLI data). The decay-exponential relationship begrowth, whether described as LNAR or GCIR, tween ADLI and DTV can, therefore, form the basis of a decision support tool for growers before planting of 'LPLS4', i.e., Eq. [3]:

$$
\mathrm{DTV}=59.2+497.7 \operatorname{Exp}(-0.4 * \text { ADLI })
$$

In addition, once planted, the combination of observed data for both DLI and LNAR can be used by growers as a post-planting, decision support tool to further refine the accuracy of prediction as the growing period progresses, i.e., Eq. [4]:

$$
\begin{aligned}
\mathrm{DTV}= & 59.01+6578 * \operatorname{Exp}(-0.1891 * \text { ADLI } \\
& -19.82 * \mathrm{LNAR})
\end{aligned}
$$

Because the DTV is developmentally a direct function of MLN*leaf initiation rate (measured as LNAR in the current experiment), the inclusion of a measure of leaf number or leaf appearance rate in the final model not only makes a mathematical improvement in the accuracy of prediction, but is also physiologically logical.

Limitation of pre-planting and postplanting models. It has been well established that temperature and photoperiod significantly influence time to flower in a range of plants (Funnell, 2008; Karlsson, 2002). However, the effect of these two variables on the DTV of 'LPLS4' has not been investigated and incorporated into the pre- and post-planting models presented here. Hence, the predictive accuracy of both the pre- and post-planting models may be reduced under conditions in which DAT cannot be controlled to $\approx 20{ }^{\circ} \mathrm{C}$ and photoperiod is shorter than $13 \mathrm{~h}$. Further research is, therefore, required to construct more comprehensive models that integrate the effects of temperature, photoperiod, and DLI.

The pre- and post-planting models can be used to predict DTV of 'LPLS4' but not DTH. Because no evident correlation was detected between ADLI and DTH, the data in Phase 2 has not been combined with the data in Phase 1 to construct such models. However, DTH remained relatively constant, varying from 47 to $68 \mathrm{~d}$ with an average of $58 \mathrm{~d}$ or $1173{ }^{\circ} \mathrm{C} \mathrm{d}$. Thus, the prediction of days from transplanting to actual harvest maturity can be achieved by adding either $58 \mathrm{~d}$ or $1173^{\circ} \mathrm{C} d$ to the predicted DTV from either of the pre- or post-planting models presented here.

\section{Conclusion}

Within the confines of temperatures and photoperiod used in the current study, growers can use the pre-planting model [i.e., DTV = $59.2+497.7 \operatorname{Exp}(-0.4 *$ ADLI $)]$ to schedule planting dates and predict flowering time of 'LPLS4' based on historical DLI data. Once planted, predicting flowering time can be further improved using the post-planting model [i.e., $\mathrm{DTV}=59.01+6578 * \operatorname{Exp}(-0.1891 *$ ADLI $19.82 *$ LNAR)].

\section{Literature Cited}

Armitage, A.M. 1984. Effect of leaf number, leaf position, and node number on flowering time in 
hybrid Geranium. J. Amer. Soc. Hort. Sci. 109: 233-236.

Armitage, A.M. 2003. Limonium perezii, p. 212 213. In: Armitage, A.M. (ed.). Specialty cut flowers: The production of annuals, perennials, bulbs, and woody plants for fresh and dried cut flowers. Timber Press, Portland, OR.

Armitage, A.M., W.H. Carlson, and J.A. Flore. 1981. The effect of temperature and quantum flux-density on the morphology, physiology, and flowering of hybrid Geraniums. J. Amer. Soc. Hort. Sci. 106:643-647.

Draper, N. and H. Smith. 1981. Multiple regression and mathematical model building, p. 412-422. In: Bradley, R.A., J.S. Hunter, D.G. Kendall and G.S. Watson (eds.). Applied regression analysis, 2nd Ed. Wiley series in probability and mathematical statistics. Wiley, New York, NY.

Fausey, B.A., R.D. Heins, and A.C. Cameron. 2005. Daily light integral affects flowering and quality of greenhouse-grown Achillea, Gaura, and Lavandula. HortScience 40:114-118.

Faust, J.E. 2003. Light, p. 71-84. In: Hamrick, D. (ed.). Ball redbook: Crop production. 17th Ed., Vol. 2. Ball Publishing, Batavia, IL.

Funnell, K.A. 2008. Growing degree-day requirements for scheduling flowering of Scadoxus multiflorus subsp. katharinae (Baker) Friis \& Nordal. HortScience 43:166-169.

Harada, D. 1992. How to grow Limonium. FloraCulture Intl. 2:22-25.
Heins, R.D., B. Liu, and E.S. Runkle. 2000. Regulation of crop growth and development based on environmental factors. Acta Hort. 511:15-20.

Karlsson, M.G. 2002. Flower formation in Primula vulgaris is affected by temperature, photoperiod and daily light integral. Sci. Hort. 95:99-110.

Korczynski, P.M., J. Logan, and J.E. Faust. 2002 Mapping monthly distribution of daily light integrals across the contiguous United States. HortTechnology 12:12-16.

Liu, B. and R.D. Heins. 2002. Photothermal ratio affects plant quality in 'Freedom' poinsettia. J. Amer. Soc. Hort. Sci. 127:20-26.

Loehrlein, M.M. and R. Craig. 2004. The effect of daily light integral on floral initiation of Pelargonium $\times$ domesticum L.H. Bailey. HortScience 39:529-532.

Mattson, N.S. and J.E. Erwin. 2005. The impact of photoperiod and irradiance on flowering of several herbaceous ornamentals. Sci. Hort. 104: 275-292.

Morgan, E.R., G.K. Burge, G. TimmermanVaughan, and J.E. Grant. 2009. Generating and delivering novelty in ornamental crops: Some examples. Acta Hort. 836:97-103.

Niu, G., R.D. Heins, A.C. Cameron, and W.H. Carlson. 2000. Day and night temperatures, daily light integral, and $\mathrm{CO}_{2}$ enrichment affect growth and flower development of pansy (Viola $\times$ wittrockiana). J. Amer. Soc. Hort. Sci. 125:436-441.
Oh, W., I.H. Cheon, K.S. Kim, and E.S. Runkle. 2009. Photosynthetic daily light integral influences flowering time and crop characteristics of Cyclamen persicum. HortScience 44:341344.

Pasian, C.C. and J.H. Lieth. 1994. Prediction of flowering rose shoot development based on airtemperature and thermal units. Sci. Hort. 59: 131-145.

Ramina, A., W.P. Hackett, and R.M. Sachs. 1979. Flowering in Bougainvillea-Function of assimilate supply and nutrient diversion. Plant Physiol. 64:810-813.

Semeniuk, P. and D.T. Krizek. 1972. Long days and cool night temperature increase flowering of greenhouse grown Limonium cultivars. HortScience 7:293.

Semeniuk, P. and D.T. Krizek. 1973. Influence of germination and growing temperature on flowering of six cultivars of annual statice (Limonium cv.). J. Amer. Soc. Hort. Sci. 98:140-142.

Shillo, R. and E. Zamski. 1985. Limonium sinuatum, p. 293-301. In: Halevy, A.H. (ed.). CRC handbook of flowering. CRC Press, Boca Raton, FL.

Volk, T. and B. Bugbee. 1991. Modelling light and temperature effects on leaf emergence in wheat and barley. Crop Sci. 31:1218-1224.

Warner, R.M. and J.E. Erwin. 2003. Effect of photoperiod and daily light integral on flowering of five Hibiscus sp. Sci. Hort. 97:341-351. 